\title{
Profile of Nosocomial Infections in the Pediatric Intensive Care Unit (PICU) of a Tertiary Care Hospital
}

\author{
Mir Mohammad Yusuf ${ }^{1 *}$ and MAK Azad Chowdhury ${ }^{2}$ \\ ${ }^{1}$ Assistant Professor, Critical Care Department, Bangladesh Institute of Child Health (BICH), Dhaka Shishu (Children) Hospital, Bangladesh \\ ${ }^{2}$ Professor and Head, Department of Neonatology, Bangladesh Institute of Child health (BICH), Dhaka Shishu (Children) Hospital, Bangladesh \\ *Corresponding Author: Mir Mohammad Yusuf, Assistant Professor, Critical Care Department, Bangladesh Institute of Child Health \\ (BICH), Dhaka Shishu (Children) Hospital, Bangladesh.
}

Received: August 29, 2019; Published: September 27, 2019

DOI: $10.31080 /$ ASPE.2019.02.0155

\begin{abstract}
Background: Nosocomial infections (NI) are those that are acquired in a hospital setting, a chain of events whereby a source of pathogens is transmitted by some method to a susceptible host, a leading preventable infectious complication with increased mortality of critically ill patients admitted in an intensive care setup. In addition extra hospital stay and expenditure thus over burdening the already strained health economy.

Method: This was a prospective observational study conducted in the pediatric intensive care unit (PICU) of Dhaka Shishu (Children) Hospital. The study group comprised 290 patients admitted for more than 48 hours in the PICU. The study was carried out for duration of six months from July 2018 to December 2018. Children between 0-12 years of age were included in this study. Blood culture positive case at the time of admission was excluded. Patients with any clinical feature suggesting nosocomial infection, detailed examination of patients eg. Temperature, pulse, blood pressure, respiratory system, abdominal examination, any purulent secretion or discharge, their blood culture and swab culture of probable sources were done.

Results: During study period, 412 patients were admitted to PICU. 290 patients with their PICU stay more than 48 hours were enrolled after exclusion criteria. 52 patients had nosocomial infections. 61.54\% (32/52) developed bloodstream nosocomial infection and 38.46\% (20/52) patient developed device related nosocomial infection. Neonates were more susceptible develop nosocomial infection ( $\mathrm{p}<0.001$, highly significant). Most of organisms (84.6\%) were gram negative bacilli, Acinetobacter was the most common pathogens (36.53\%) followed by Klebsiella (15.38\%), Pseudomonas (15.38\%), E-coli (7.69\%). Candida (15.62\%) were found. Microorganisms were more sensitive to netilmycin and ciprofloxacin followed by meropenem against these organisms. Nosocomial infections increase hospital mortality ( $\mathrm{p}<0.01$, significant) and extra hospital stay (mean hospital stay days 12.03 ) in comparison to non-nosocomial infection (mean hospital stay days 8.09).

Conclusions: Nosocomial infection in critically ill patient of PICU is an important preventable infectious complication of increased mortality led to extra hospital stay and expenditure, more with use of invasive device.

Keywords: Nosocomial Infection; PICU
\end{abstract}

\section{Introduction}

Intensive care units are to provide the advanced medical services to critically ill patients. The application of advanced technology is not without hazards and among these, hospital acquired (nosocomial) infections are common complications of admission to an intensive care unit. Nosocomial infections are generally a chain of events whereby a source or reservoir of microorganisms is transmitted to a susceptible host by some method including hospital staff, equipment or even food, water, walls, floor, and some other surfaces [1]. Nosocomial infections that develop are neither present nor incubating at the time of admission and developing 48 hours or more after admission [2]. It constitutes a major health problem with high mortality, a matter of serious concern today. In addition to extra hospital stay and increase of health cost, especially in paediatric intensive care unit (PICU) [3,4]. A majority of it occur in neonate that require an intensive care [5]. Patient are more likely to acquire nosocomial infections due to their underlying disease with resulting impairment of humoral and cellular immunity and the invasive procedures that they undergo which breakdowns their natural defense barriers [6]. Bloodstream infections are the most common infections in PICU [7]. It is independently associated with a three-fold increased risk of death [8]. Device associated nosocomial infections also frequently occur in PICU and NICU [9]. Isolation of pathogens from equipment and fomites evidenced that they can be sources of infection to patients [10]. Empiric antibiotic treatment from early reduces mortality in sepsis.11 But knowledge 
about local pathogens and their sensitivity is essential in empiric treatment. The antibiotic resistance of nosocomial infections is rapidly increasing. Nosocomial infection with multidrug resistant pathogens are difficult to treat and are associated with increased mortality [11]. Progressive antimicrobial resistance threatens primary treatment approach against bacterial pathogens [12]. Serious medicolegal issues also arise in this context, since the patient or their families sometimes blame the hospital for the infection $[13,14]$. To minimize the infection in PICU with optimal cost effective care, every ICU should have its own strategy for prevention and treatment of such nosocomial infection. In our setting that of a busy ICU in a tertiary care hospital in the public sector, survey of nosocomial infection has not been carried out properly in the recent past. The objectives of the present study were to determine the rate of nosocomial infection, identify possible risk factors for these infections, to clarify the distribution of causative pathogens and to evaluate the outcome of the infected patients in terms of length of ICU and hospital stay and mortality.

\section{Subject and Methods}

This study was carried out in the PICU of Dhaka Shishu (Children) Hospital having for pediatric age group of children during study period from July 2018 to December 2018. Children aged $0-12 y$ rs of both sexes who had fulfilled the following criteria were enrolled in the study. Before enrollment, parent of each child was given a detail explanation about the nature and purpose of the study. The study was started after obtained ethical clearance by Ethical Review Committee of Dhaka Shishu (Children) Hospital. The exclusion criteria included (a) blood culture positive case at the time of admission, (b) children died or discharged within 48 hours of admission, (c) not interested to receive management or to continue participate in the study. Patients were followed up and examined every day to observe the development of any signsymptoms of nosocomial infections, when clinically suspected to have nosocomial infections, their blood sample were taken aseptically and culture and sensitivity was done. Those children who were culture positive, considered development of nosocomial infections. Swab were taken from the probable source such as endotracheal tube, IV canula, catheter tip, drain tube, wound swab and culture-sensitivity test were done. Other investigations were done as needed. PICU acquired nosocomial infection were defined according to Centre for Diseases Control and Prevention (CDC) [15]. Infections that commenced after 48 hours of admission to PICU were termed as PICU acquired (nosocomial) infections. Nosocomial bloodstream infections were put on according to biological documentation of infection e.g, positive blood culture [15]. Data were analyzed using categorical variables, evaluated and using the chi-square test, as appropriate. p-value of $<0.05$ was considered significant.

\section{Results}

A total of 412 admissions to PICU occurred during the study period of six months, 290 patients fulfilled the inclusion criteria. Out of 290 patients, $64.14 \%$ (186) were male and $35.86 \%$ (104) were female. Neonates were $37.93 \%$ (110) and non-neonates beyond $1 \mathrm{st}$ month up to 12 years were $62.07 \%$ (180).

Out of 290 patients, $17.93 \%$ (52) developed nosocomial infection. $11.03 \%$ (32) developed nosocomial bloodstream infection confirmed by blood culture (Table 1). Predominate isolates(blood culture positive), $78.12 \%$ (25) were gram negative bacteria, Acinetobacter and Klebsiella were common pathogens of each 7(28\%) followed by Candida 15.62\% (5), Pseudomonas 12.5\% (4), E-coli $8 \%$ (2) (Table 2). Swab culture from the probable sources (fomites or devices) used by admitted children as endotracheal tube, catheter tip, IV canula, wound swab, drain tube tip showed that gram negative bacteria were the predominate microorganisms. The most common pathogens in swab culture were Acinetobacter 60\% (12) followed by Pseudomonas 20\% (4), E-coli 10\% (2), Klebsiella 5\% (1), Staphylococci 5\% (1) (Table 2). Organisms obtained from blood culture were high résistance to ampicillin, amoxicillin, azithromy$\operatorname{cin}$

In this study, $28.18 \%$ (31) neonates developed nosocomial infection whereas $11.66 \%$ (21) children (non-neonates) are more susceptible to develop nosocomial infection (Table 2), $\mathrm{p}<0.001$, highly significant during the study (Table 1).

Mean hospital stay of nosocomial infection patients days 12.03 whereas non-nosocomial infection patients were days 8.09 (Table 1).

Out of 290 patients, $6.89 \%$ (20) patients received left against medical advice (LAMA). Among 270 patients 89.26\% (241) improved and $10.74 \%$ (29) died. 52 patients who developed nosocomial infections $23.08 \%$ (12) died and among 218 patients without nosocomial infection $7.8 \%$ (17) died. The difference is statistically significant $(\mathrm{p}<0.01)$ (Table 4$)$.

\section{Discussion}

Nosocomial infections are becoming an increasing problem, both for the hospitalized patient's as well as the hospital. Nosocomial infections are five times more common in ICU patients. So the prevention of ICU acquired infections demands knowledge of the infection rates and of the sources, the pathogens involved as well as the common risk factors for infection. A large cohort multicentric international study has reported at least one ICU acquired infection in $18.9 \%$ of patients, with ranging from $2.3 \%$ to $49.2 \%$ across the centers [15]. In our study, it was $17.93 \%$. Comparable with other 


\begin{tabular}{|c|c|c|}
\hline Characteristics status & Frequency & Percent \\
\hline $\begin{array}{l}\text { Age (month) } \\
\text { Neonates (upto 1st month) } \\
\text { Non-neonates (>1st month upto } 12 \text { yrs) }\end{array}$ & $\begin{array}{l}110 \\
180\end{array}$ & $\begin{array}{l}37.93 \\
62.07\end{array}$ \\
\hline Total & 290 & 100.00 \\
\hline $\begin{array}{l}\text { Sex }(M / F) \\
\text { Male } \\
\text { Female }\end{array}$ & $\begin{array}{l}186 \\
104 \\
\end{array}$ & $\begin{array}{l}64.14 \% \\
35.86 \% \\
\end{array}$ \\
\hline Total & 290 & 100.00 \\
\hline $\begin{array}{l}\text { Status of Nosocomial infection } \\
\text { Positive } \\
\text { Negative }\end{array}$ & $\begin{array}{c}52 \\
238\end{array}$ & $\begin{array}{l}17.93 \\
82.07\end{array}$ \\
\hline Total & 290 & 100.00 \\
\hline $\begin{array}{l}\text { Status of bloodstream Nosocomial infection } \\
\text { Positive } \\
\text { Negative }\end{array}$ & $\begin{array}{c}32 \\
258\end{array}$ & $\begin{array}{l}11.03 \\
88.97\end{array}$ \\
\hline Total & 290 & 100.00 \\
\hline $\begin{array}{l}\text { Status of Non-bloodstream Nosocomial infection (device related) } \\
\text { Positive } \\
\text { Negative }\end{array}$ & $\begin{array}{c}20 \\
270\end{array}$ & $\begin{array}{c}6.90 \\
93.10 \\
\end{array}$ \\
\hline Total & 290 & 100.00 \\
\hline $\begin{array}{l}\text { Mean Hospital stay (days) } \\
\text { Nosocomial } \\
\text { Non-nosocomial }\end{array}$ & $\begin{array}{c}12.03 \\
8.09\end{array}$ & \\
\hline
\end{tabular}

Table 1: Baseline profile of the study population.

\begin{tabular}{|l|c|c|c|}
\hline \multirow{2}{*}{\multicolumn{1}{|c|}{ Age }} & \multicolumn{2}{c|}{ Nosocomial infection } & \multirow{2}{*}{ Total } \\
\cline { 2 - 3 } & Positive & Negative & \\
\hline Neonates (upto 1st month) & $31(28.18 \%)$ & $79(71.82 \%)$ & $110(100.00)$ \\
Non-neonates(>1st month-12years) & $21(11.66 \%)$ & $159(88.33 \%)$ & $180(100.00)$ \\
\hline Total & 52 & 238 & 290 \\
\hline
\end{tabular}

Table 2: Age of child and nosocomial infection status.

Chi-square=12.64; $\mathrm{df}=1 ; \mathrm{p}<0.001$ (highly significant)

Neonates are more susceptible to develop nosocomial infections than children aged beyond $1^{\text {st }}$ month $(\mathrm{p}<0.001)$.

\begin{tabular}{|l|c|c|}
\hline Gram negative & 7 & 21.88 \\
Acinetobacter & 7 & 21.88 \\
Klebsiella & 4 & 12.50 \\
Pseudomonas & 2 & 6.25 \\
E-coli & 2 & 6.25 \\
Citrobacter & 2 & 6.25 \\
Salmonella & 1 & 3.13 \\
Serratia & & \\
Gram Positive & 1 & 3.13 \\
Staphylococci & 1 & 3.13 \\
Streptococci & 5 & 15.6 \\
Candida & $\mathbf{3 2}$ & $\mathbf{1 0 0}$ \\
\hline Total & & \\
\hline
\end{tabular}

Table 3: Profile of pathogens in blood-culture positive cases ( $n=32)$.

\begin{tabular}{|l|c|c|c|c|c|}
\hline \multicolumn{1}{|c|}{ Culture } & \multicolumn{4}{|c|}{ Sources (fomites) } & $\begin{array}{c}\text { Total } \\
\text { (n) }\end{array}$ \\
\hline & $\begin{array}{c}\text { ET } \\
\text { tube }\end{array}$ & $\begin{array}{c}\text { Catheter } \\
\text { tip }\end{array}$ & $\begin{array}{c}\text { Wound } \\
\text { swab }\end{array}$ & $\begin{array}{c}\text { Drain } \\
\text { tube }\end{array}$ & Total \\
\hline Gram negative & & & 1 & & \\
Acinetobacter & 11 & & 1 & & \\
Pseudomonas & 3 & 1 & & & \\
Klebsiella & 1 & 1 & 2 & 1 & 20 \\
E-coli & 16 & 1 & & & \\
Gram positive & & & & & \\
Staphylococcus & & & & & \\
\hline Total & 16 & & & & \\
\hline
\end{tabular}

Table 4: Profile of pathogens isolated from sources (fomites) of patients. 


\begin{tabular}{|l|c|c|c|c|c|c|c|c|c|c|c|}
\hline Organisms & $\begin{array}{c}\text { Mero } \\
\text { penem } \\
\mathbf{\%}\end{array}$ & $\begin{array}{c}\text { Ami } \\
\text { kacin } \\
\mathbf{\%}\end{array}$ & $\begin{array}{c}\text { Netil } \\
\text { mycin } \\
\mathbf{\%}\end{array}$ & $\begin{array}{c}\text { Cefta } \\
\text { zidim } \\
\mathbf{\%}\end{array}$ & $\begin{array}{c}\text { Chloram } \\
\text { phenicol } \\
\mathbf{\%}\end{array}$ & $\begin{array}{c}\text { Cipro- } \\
\text { floxacin } \\
\mathbf{\%}\end{array}$ & $\begin{array}{c}\text { Cotri- } \\
\text { moxazol } \\
\mathbf{\%}\end{array}$ & $\begin{array}{c}\text { Pipera- } \\
\text { cilin } \\
\mathbf{\%}\end{array}$ & $\begin{array}{c}\text { Ceftrix- } \\
\text { on } \\
\mathbf{\%}\end{array}$ & $\begin{array}{c}\text { Imip } \\
\text { enem } \\
\mathbf{\%}\end{array}$ & $\begin{array}{c}\text { Levoflox- } \\
\text { acin } \\
\mathbf{\%}\end{array}$ \\
\hline $\begin{array}{l}\text { Acinetobacter } \\
\text { Resistant to all } \\
21.05 \%\end{array}$ & 5 & 11 & 42 & 21 & 5 & 21 & 32 & 16 & 11 & 0 & 21 \\
\hline Klebsiella & 38 & 50 & 50 & 0 & 38 & 25 & 50 & 13 & 13 & 38 & 50 \\
\hline Pseudomonus & 13 & 25 & 25 & 25 & 0 & 50 & 0 & 25 & 13 & 25 & 25 \\
\hline E-coli & 50 & 50 & 50 & 50 & 25 & 25 & 25 & 0 & 0 & 25 & 25 \\
\hline Serratia & 100 & 100 & 100 & 100 & 0 & 100 & 100 & 0 & 100 & 100 & 0 \\
\hline Salmonella & 0 & 0 & 0 & 50 & 50 & 100 & 50 & 0 & 100 & 0 & 50 \\
\hline Citrobacter & 100 & 100 & 100 & 100 & 100 & 100 & 100 & 50 & 100 & 0 & 50 \\
\hline Streptococci & 0 & 0 & 0 & 0 & 0 & 0 & 100 & 50 & 100 & 0 & 100 \\
\hline Staphylococci & 50 & 0 & 0 & 0 & 50 & 0 & 0 & 0 & 0 & 50 & 0 \\
\hline
\end{tabular}

Table 5: Sensitivity profile of microorganisms.

*Candida is not shown in the table

\begin{tabular}{|l|c|c|c|}
\hline \multirow{2}{*}{ Outcome of treatment } & \multicolumn{2}{|c|}{ Nosocomial infection } & \multirow{2}{*}{ Total } \\
\cline { 2 - 3 } & Positive & Negative & \\
\hline Improved & $40(76.92 \%)$ & $201(92.20 \%)$ & $241(89.26 \%)$ \\
Deceased & $12(23.08 \%)$ & $17(7.80 \%)$ & $29(10.74 \%)$ \\
\hline Total & $52(100.00)$ & $218(100.0 \%)$ & $270(100.0 \%)$ \\
\hline
\end{tabular}

Table 6: Outcome of treatment between with and without nosocomial infection.

Chi-square $=10.22 ; \mathrm{df}=1 ; \mathrm{p}=<0.01$ (significant).

study, it was $22.1 \%$ with Porto., et al. [3] and $21.4 \%$ with Wahab., et al. [16]. However, the rate of infections varied considerably according to the country, with Greece and Portugal having the highest and Switzerland, Germany and the Netherlands having the lowest infection rates [17]. Other studies have reported rates between $9 \%$ [18] and 37\% [19] depending largely on the populations studied. The findings in our study were found to be closer to the lower range reported in other studies referred above. This difference in findings is not necessarily related to better quality of care, since many other factors may be responsible including difference in the criteria for patient selection, ICU type, severity of illness, length of stay, rate of device utilization [20-22].

In this study showed extra length of hospital stay with nosocomial infections more than non-nosocomial infection admitted in PICU. Mean hospital stay days 12.03 in nosocomial infection comparison to mean hospital days 8.09 in non-nosocomial. So length of hospital stay of children with nosocomial infection in PICU in our study was about four days more than children. It increases extra financial burden of the patient $[23,34]$. Proper preventive measures through specific intervention may reduce ICU treatment cost of these infections.

In the study, 31(28.18\%) children (neonates) developed nosocomial infection and 21 (11.66\%) children (non-neonates) developed nosocomial infection indicates neonates are more susceptible to develop infection than children (non-neonates), Similar to other studies $[25,26]$.

The precise pattern of causative organisms, whether bacterial or fungal, varies across countries and between ICUs according to patient case, site of infection, antibiotic protocols, infection control practice and local ecology and resistance patterns [27]. Still most studies report that more than half of nosocomial infections occurring in PICU are due to gram negative bacteria $[17,21]$ especially in developing countries $[3,4,6,11,28]$. In our study too, the most commonly isolated organisms were Gram negative Enterobacteriacae followed by Candida and Gram positive. Although recent years have been swings in pathogen pattern toward Gram-positive bacterial infections $[29,30]$. The detection of Candida in $10 \%$ of isolates in the present study is also consistent to some extent with the studies of Pittet and Wengel [31] and Edgeworth., et al. [32] who have reported that fungal pathogens are also becoming increasingly common among patients with nosocomial bloodstream infections.

Antimicrobial resistance to common pathogens has alarming and negative impact on outcome and extra stay of hospitalization with health care expenditures burden [33]. Some study showed isolated pathogens in PICU were shown resistant to third generation cephalosporin [34]. Carbapenems e.g Meropenem, Imipenem are reliable antibiotic options for nosocomial infections. According to 
WHO report [33], Acinetobacter and Klebsiella were almost 100\% sensitive to carbapenems in Bangladesh. E-coli are $41 \%$ and Klebsiella were $2.2 \%$ sensitive to ceftriaxon in Bangladesh. In our study 11\% Acinetobacter, 13\% Klebsiella and 13\% E-coli were sensitive to ceftriaxone. Ceftazidim and amikacin were relatively better sensitive to pseudomonas and E-coli than Klebsiella and Acinetobacter. In our study, netilmycin and ciprofloxacin were more sensitive antibiotic option to nosocomial infection and $21.05 \%$ Acinetobacter was resistant to all type of antibiotics.

Role of fomites eg. central like associated bloodstream infections, ventilator associated pneumonia and catheter-associated urinary tract infections in spread of nosocomial infections has been noticed in PICU patients in different studies [8,9,35]. In our study fomites specially health care device like IV canula, endotracheal tube, drain tube, catheter tip are considered to be important sources of nosocomial infection in PICU patients.

\section{Conclusion}

Nosocomial infections are an important preventable infectious complication leading cause of mortality in paediatric intensive care unit (PICU) and extra duration of hospital staying, increase with use of invasive device

\section{Bibliography}

1. Feigin RD and Cherry RD. "Textbook of pediatrics infectious diseases". 1st Ed.WB Saunders Company, Philadelphia 2 (1981): 1655-1693.

2. Chin-Hong PV and Guglielmo BJ. "Common Problems in Infectious Diseases and Antimicrobial Therapy". In: Papadakis MA. Mcphee SJ, editors. Current Medical Diagnosis and Treatment 2016. 55th edition. USA: Mc Graw-Hill education (2016): 1267-1309.

3. Porto JP., et al. "Nosocomial infections in a pediatric intensive care unit of a developing country: NHSN surveillance". 45 (2012).

4. Hamed AK., et al. "Nosocomial infections and antibiotic administration in pediatric department, Imam Reza Hospital, Mashhad, Iran". International Journal of Pediatrics 2.2 (2014): 157-161.

5. Chusid MJ and Rotar MM. "Infection prevention and control". In: Kliegman RM, Stanton BF, Geme JMS. Schor NF, editors. Nelson textbook of pediatrics. 20th edition. Philadelphia, Pennsylvania: Elsevier (2016): 1260-1263.

6. Pourakabari B., et al. "Epidemiology of nosocomial infections in pediatric patients". Iranian referral hospital 53 (2012): 204206.
7. Prowle JR., et al. "Acquired bloodstream infection in the intensive care unit: incidence and attributable mortality". Critical Care 15.2 (2011): 100.

8. Navaeifar MR and Rezai MS. "Device associated nosocomial infection in children". Journal of Pediatric Review 1.2 (2013): 25-41.

9. Ikeh EI and Isamade ES. "Bacterial Flora of Fomites in a Nigerian Multi disciplinary Intensive Care Unit". Lab Medicine 42 (2011): 411-413.

10. Ferrer R., et al. "Empiric antibiotic treatment reduces mortality in severe sepsis and septic shock from the first hour: results from a guideline-based performance improvement program". Critical Care Medicine 42 (2014): 1749-1755.

11. Ahmed B., et al. "Standard management guideline for Infectious diseases in Bangladesh: Directorate General of Health Services, Bangladesh" (2013).

12. House of Commons Committee of Public Accounts. The management and control of hospital acquired infection in acute NHS trusts in Enlangd (2003).

13. Haley RW., et al. "The efficacy of infection surveillance and control programs in preventing nosocomial infections in US hospitals". American Journal of Epidemiology 121 (1985): 182-205.

14. Varsha SA., et al. "Incidence of nosocomial infection in the pediatric intensive care unit of a teaching hospital delivering tertiary level care". International Journal of Contemporary Pediatrics 4.2 (2017): 332-335.

15. Alberti C., et al. "Epidemiology of sepsis and infection in ICU patients from an international multicentre cohort study". Intensive Care Medicine 28 (2002): 108-121.

16. Wahab FA., et al. "Nosocomial infection surveillance in an Egyptian neonatal intensive care unit". The Journal of Hospital Infection 83.3 (2013): 196-199.

17. Vincent JL. "Nosocomial infections in adult intensive care units". Lancet 361 (2003): 2068-2077.

18. Rebollo MH., et al. "Nosocomial infections in patients having cardiovascular operations: A multivariate analysis of risk factors". The Journal of Thoracic and Cardiovascular Surgery 112 (1996): 908-913.

19. Papia G., et al. "Infection in hospitalized trauma patients: incidence, risk factors, and complications". Journal of Trauma 47 (1999): 923-927. 
20. Erbay H., et al. "Nosocomial infections in intensive care unit in a Turkish university hospital: A 2-year survey". Intensive Care Medicine 29 (2003): 1482-1488.

21. Richadrs MJ., et al. "Nosocomial infections in medical infections surveillance system". Critical Care Medicine 27 (1996): 887-892.

22. Richadrs MJ., et al. "Nosocomial infections in combined medical-surgical intensive care units in the United States". Infection Control and Hospital Epidemiology 21 (2000): 510-515.

23. Pittet D., et al. "Nosocomial bloodstream infection in critically ill patients. Excess length of stay, extra costs, and attributable mortality". JAMA 271 (1994): 1598-601.

24. Correa L and Pittet D. "Problems and solutions in hospitalacquired bacteraemia”. Journal of Hospital Infection 46 (2000): 89-95.

25. Die-Bok., et al. "Nosocomial infections in a neonatal intensive care unit in south Brazil". Revista Brasileirater intensive 24.4 (2012): 381-385.

26. Suljagic V., et al. "Nosocomial bloodstream infection in ICU and non ICU patient". American Journal of Infections Control 35 (2005): 333-334.

27. Vincent JL., et al. "The extended prevalence of infection in the ICU study: EPIC II". JAMA 302 (2009): 2323-2329.

28. Davoudi AR., et al. "Frequency of bacterial agents isolated from patients with nosocomial infection in teaching hospitals of Mazandaran University of medical sciences in 2012'. Caspian Journal of international medicine 5.14 (2014): 227-231.

29. Friedman G., et al. "Has the mortality of septic shock changed with time”. Critical Care Medicine 26 (1998): 2078-2086.

30. Edmond MB., et al. "Nosocomial bloodstream infections in United States hospitals: A three-year analysis". Clinical Infection Disease 29 (1999): 239-244.

31. Pittet D and Wenzel RP. "Nosocomial bloodstream infections. Secular trends in rates, mortality, and contribution to total hospital deaths". Archives of International Medicine 155 (1995): 1177-1184.

32. Edgeworth JD., et al. "A 25-year study of nosocomial bacteremia in an adult intensive care unit". Critical Care Medicine 27 (1999): 1421-1428.

33. WHO. Antimicrobial resistance: global report on surveillance (2014).
34. Radji M., et al. "Antibiotic sensitivity pattern of bacterial pathogens in the intensive care of Fatmawati Hospital, Indonesia". Asia pacific Journal of tropical Biomedicine 1.1 (2011): 39-42.

35. Leblebicioglu H., et al. "International Nosocomial Infection Control Consortium (INICC) national report on device associated infection rates in 19 cities of Turkey, data summary for 2003-2012". Annals of Clinical Microbiology and Antimicrobials 13 (2014): 51.

\section{Volume 2 Issue 10 October 2019}

C All rights are reserved by Mir Mohammad Yusuf and MAK Azad Chowdhury. 